\title{
Analysis on the Problems of Underground Forest Attraction Management in North Scenic Area of Changbai Mountain
}

\author{
Mingju Liu \\ Yatai school of Business Administration \\ Jilin University of Finance and Economics \\ Changchun, China 130117
}

\author{
Liguang Zhao \\ School of Taxation \\ Jilin University of Finance and Economics \\ Changchun, China 130117
}

\author{
Kai Wang \\ Yatai school of Business Administration \\ Jilin University of Finance and Economics \\ Changchun, China 130117
}

\begin{abstract}
Based on the existing problems in the management of scenic spots in China, this paper analyzes the current situation and the management of north scenic spots of Changbai Mountain. It points out the existing problems and has put forward corresponding solutions to the innovation of the management of scenic areas, and to promote the sustained and good development of tourist attractions of Changbai Mountain.
\end{abstract}

Keywords-North scenic area of Changbai Mountain; Management of tourist attractions; staff management; tourist management

\section{INTRODUCTION}

Forest tourism has started in China in 1980s. In recent years, it has developed rapidly. In 2016, there are 2583 forest parks in China. And there are 740 national forest parks. There is only one national forest tourist area. In China's list of world natural and cultural heritage, there are 15 landscape resources covering forest parks. And there are 15 forest parks in world geological park list. With the rapid development, forest tourism has also attracted a lot of social investment at the same time. Gradually, it has begun to develop forest tourism in all parts of the country with their advantages and the unique forest tourism resources.

\section{THE CONCEPT AND METHOD OF MANAGEMENT OF FOREST SCENIC AREA}

\section{A. The Concept of Management of Forest Attractions}

The management of tourist attractions refers to the effective allocation of various resources and the coordination of the various relationships in the scenic areas through planning, organization, control, stimulation and

Fund Project: National Natural Science Foundation of China (Project No .: 41401146); Jilin Province Science and Technology Development Project (201502040NY). Department of Education Project of Jilin Province. (JJKH20170140SK). leadership and other ways. And it is developed with the inherent characteristics and laws of the scenic areas. Also, it is developed with the basic functions of management and the needs in different development stages. And the managers in scenic areas would arrange reasonable human, material and financial resources to achieve the objectives of reserve process through effective management.

\section{B. The Ways of Management of Forest Attractions}

\section{1) Economic Management}

Within the tourist attractions, it makes the arrangement through certain economic means. For example, it should adopt the effective welfare policy. And it should adopt the correct scenic management to guide employees. Also, it can carry out the reward mechanism to encourage the tourists to have tourism activities in scenic attractions.

\section{2) Safety}

The international tourist attractions pay much attention to the safety. In underground forest attractions of north scenic areas of Changbai Mountain, security issues are the most important in all work. All the employees in tourist attractions have regarded forest fire protection, tourist safety, facilities maintenance as a top priority for the work.

\section{3) Coordinate Management}

The unified management in hierarchical level: coordination and management is used in the daily management work in underground forest attractions of north scenic areas of Changbai Mountain. In the underground forest attractions, there are many employees allocated in many positions of the underground forest attractions. Through the hierarchical unified management not only greatly improves the efficiency of the tourist attractions, but also effectively prevents the occurrence of emergencies. 


\section{4) Administrative Management}

The industry executives in the scenic areas partly set up special management functions. And they would make the overall planning and supervision of the scenic areas with the use of various administrative means.

\section{CURRENT SITUATION OF UNDERGROUND FOREST ATTRACTION MANAGEMENT OF NORTH SCENIC AREAS OF ChangBai MOUNTAIN}

\section{A. The Introduction of Underground Forest Attractions of} North Scenic Area of Changbai Mountain

\section{1) The Introduction of North Scenic Area of Changbai}

\section{Mountain}

Changbai Mountain is located in the northeast of the motherland, in Fusong county of Baishan city, Jilin province, and in Antu county of Korean autonomous prefecture of Yanbian area, and is one of China's top ten mountains. And it is also the mountain between China and North Korea. It is called the first mountain of kantox area. It is known for thousands of years of snow and years of pine trees, and is the first peak in the world. Changbai Mountain is also the highest volcano in northeastern China. And it has the largest spout. Changbai Mountain is the birthplace of Manchu, and it is the "Holy Land" in the Qing dynasty. In 2007, it has become AAAAA national tourist attraction of the first national scenic areas.

North Scenic Area of Changbai Mountain has typical characteristics of volcanic landscape. And it is located in Tianchi Lake and the north of small Tianchi Lake. The landscape is dominated by the forest landscape of the plant vertical landscape. Changbai Mountain is rich in ginseng, Schisandra and other herbs. And it is "species gene bank" and "natural museum" in the world. Changbai Mountain is the source of the Tumen River, the Yalu River and the Songhuajiang River. Tianchi Lake of the famous Changbai Mountain is located at the top of the main peak of the Changbai Mountain volcano. It is the highest volcanic lake in Guinness World Records. Tianchi Lake is surrounded by mountains, and it is clear. The main tourist attractions are: Changbai Mountain Alpine Garden, Changbai Mountain Tianchi, Changbai Waterfall, Changbai Mountain Canyon, Changbai Mountain underground forest, underground forest group, Black outlet, Tianchi Monster and surrounding attractions.

At present, the development of tourism resources in the northern scenic area of Changbai Mountain is still based on the closed tour on natural tourism.

2) The Introduction of Underground Forest Attractions of North Scenic Area of Changbai Mountain

The underground forests are in the northern slope of Changbai Mountain. And it is in the north side of the cave waterfall. And it is the lowest scenic area of Changbai Mountain. With the eruption of main volcanic cone of Changbai Mountain, the parasitic crater is cut. With the external dynamic and other geological activities, it has resulted in the formation of collapse in a large area. And then, it has formed a huge valley. And the whole forest also sank into the bottom. Then there are underground forests.
There are many ancient trees and interlaced stones in the bottom. And the river is across the bottom of the valley. It is like a silver and jade belt, stretching toward the distant places. If you stand at the observation platform, you would be relaxed and happy, suddenly enlightened in the overlooking of the distant places.

There are boschniakia rossica and other expensive plants in the bottom of Valley of Changbai Mountain. With good luck, it can also see the sika deer, wild boar, black bear and other pure wild animals.

\section{B. The Status Quo of Management of Underground Forest Attraction of Northern Scenic Area of Changbai Mountain}

At present, Tianchi is still the focus of the scenic tourism development of Changbai Mountain. The tour of the northern scenic attractions is based on the closed tour of natural landscape. It hasn't conducted the development in comprehensive depth. On the one hand, it is caused by the tourism management awareness and the corresponding coordination of human resources. On the other hand, it is also for environmental protection and other aspects of consideration. At present, the current situation of management of underground forest attractions of north scenic area of Changbai Mountain is as the following:

\section{1) Organizational Structure}

North scenic area of Changbai Mountain is directly under the responsibility of the chairman of the scenic area. It sets up general manager of the scenic area. And it sets up underground forest management office in underground forest attractions. Also, it sets up the engineering department, marketing department, security department, finance department, auditing department and information department. And it has centralized management in a busy season.

\section{2) Management Procedures}

The management procedures of underground forest attractions of north scenic area of Changbai Mountain are shown as the followings:

- Without any pretext, no unit or individual may destroy the natural vegetation, historical relics, buildings and all natural landscapes in the scenic area and its surrounding protected areas;

- In the scenic area and its surrounding areas, it is forbidden to build industrial facilities and projects that pollute the environment. It is forbidden to discharge pollutants into the above ranges. And the departments should strengthen the protection of vegetation in the daily work;

- To set up stalls in the scenic area should be in strict control. If it needs to set up the stalls, it must make the report to the management department of scenic area to get the approval. And the stalls should operate the business according to the provisions of the relevant procedures. 
- In the scenic area, to set up outdoor advertisement must be reported to the relevant departments for approval procedures. And it must be set up in the designated locations and data;

- Any units and individuals can't destroy scenic area and the natural vegetation in its surrounding areas. Also, they can't destroy the trees in scenic areas. Due to scenic construction, renewal of tree species, and the landscape and security, the cut trees should be approved by the management department of scenic area. And then, it can operate this thing in accordance with the provisions of the relevant departments;

- Any unit and individual should obey the supervision of scenic attractions and the management of the employees. They can't deliberately obstruct, siege, and assault administrative staff. The offenders shall be held responsibilities by the public security and the judiciary. The administrative staff must wear law enforcement signs or show produce documents;

- The employees of the management department of scenic area are the supervisors. If the employees abuse the rights and play favoritism, they should be given the administrative sanctions by the units or higher authorities. If the employees make a crime, they should be responsible for the law of criminal liability.

\section{Development and Utilization of Underground Forest Attractions of Northern Scenic Area of Changbai Mountain}

In recent years, the tourism development of underground forest attractions of Changbai Mountain is mainly sightseeing tour of underground forest. A few years ago, underground forest attractions of Changbai Mountain are divided into two lines. It includes large circle line and small circle line. The grand circle is the plank road to connect the waterfall and underground forest and the gate of mountains. There is magnificent scenery and beautiful scenery along the road. However, it is closed with debris flow, floods, landslides and other natural disasters. It has been out of repair for long years.

Therefore, the tourists can only visit the small ring line in underground forest attractions of north scenic area of Changbai Mountain. The total length is $3 \mathrm{~km}$. It should spend about one to two hours in the tour. There are mainly beauty pine, Changbai Larix olgensis, vulture, root bouldering, alpine rose flowers, bottom forest, cold spring of Changbai Valley, Jinxian spring, Yuquan spring, Yaoshui spring along this road. Various attractions have their own characteristics. Sometimes, it is magnificent. Sometimes, it is mild. Sometimes, it shows unique ingenuity. And then, people would stop and enjoy the scenery. Every tourist is conquered by the nature. The mountains have the spirit with the water. The advantages of Changbai Mountain are underground forest and cold spring. It shows interpretation of the ice and the fire. And the cold spring of underground forest is the representative of the ice. It makes people feel chilly cold in summer. So, it is the most advantage of Changbai Mountain attractions. The valley wall of the bottom forest is 50-60 meters high. The trees are divided into three levels. The volcanic crater forest park is named as the bottom forest. Generally speaking, it is known as underground forest. The bottom is 2500-3000 meters. There is coniferous forest in the bottom of valley. There are unknown coniferous forests. And there are also tall and straight trees into the sky. There are young branches of the young trees around the wild and ancient trees. And all of the trees have shown natural beauty and wild beauty. A storm in the 1980s made thousands of trees here is destroyed. The branches of the ancient trees are uprooted, cut, or slopped. And all the trees are rotten. However, all the trees keep the postures. The trees and bushes in the nature reserve can't be changed artificially. Otherwise, it is illegal. And the fallen trees are strong. No one attempts to transport these trees outside the mountains. And some trees have been lying there for a hundred years.

\section{PROBLEMS IN THE DEVELOPMENT OF UNDERGROUND FOREST ATTRACTIONS OF NORTH SCENIC AREA OF CHANGBAi MOUNTAIN}

\section{A. Scenic Management Issues}

At present, the personnel allocation system of north scenic area of Changbai Mountain is relatively mature. The staff flow is relatively small. However, there is no distinction between administrative authority and organizational authority in China's tourism industry. It has resulted in vague administration authority and shadow area of the supervision. And they would blame each other in the management of underground forest attractions. For example, it lacks connections and communication among the various parts of scenic areas. The different departments are under the jurisdiction of different government departments. For example, forest areas are governed by the forestry sector management. And the underground forest area is governed by the land and resources management. It has resulted in redundant stack of government affairs. To a certain extent, it has caused the irrational management of the scenic area.

\section{B. The Management of Underground Forest Staff}

\section{1) Staff treatment is not equal}

The employees are divided into formal and temporary workers. There are differences between the formal workers and temporary workers. Even though they do the same work, they would get the different salary. And some of the temporary workers have been working for more than ten years. With the problems of the management system, the treatment of these temporary workers will be much worse than that of official workers. To some extent, it has combated the enthusiasm of the staff. It has resulted in negative slack, mutual prevarication among employees. And it has reduced the productivity. In the final, there are redundant employees. And the work efficiency is low.

2) To implement rotation system in underground forest attractions

The work of the underground forest staff is mainly to clean up 3- kilometers road. And they also should maintain 
tour order, and explain attractions and do other things. Every day, it would implement the rotation system in all the works. The rotation system has unparalleled advantages. Generally speaking, it is a more equitable. However, it will lead that job responsibilities are not clear. And the efficiency is low. The prevarication among the staff is great. The drawbacks of the work system will be transmitted to the service quality of scenic attractions. In the end, it would ultimately damage the interests of enterprises and the experience of the tourists.

\section{The Issues of Tourists of Underground Forest Attractions}

The tourism of Changbai Mountain is divided into busy seasons and slack seasons. The tourist season is from June to July. In the peak stage, daily traffic can reach more than 20,000 people, which makes a severe test for the capacity of tourists in the scenic areas. The underground forest tour line is a $3 \mathrm{~km}$ long plank road. There are several questions in the management of the tourists.

\section{1) The deficiency of tourist education and guidance}

The underground forest path along the cliff is long. Some sections of the road are completely closed. The tourists would go across the fence when they encounter a crossing. And then, it has caused a certain threat for the safety of tourists. And in valleys, tourists usually don't listen to the warning that the tourists can't be closed to the river. If there is an accident, it would have bad influences on the image of Changbai Mountain. In addition, the road is narrow. And before 12:00, it would only open half of the road in the scenic attractions. And it is $1.5 \mathrm{~km}$ long. And the tourists have to return back in the original way when they arrive at the bottom of the underground forest. It would make the tourists enjoy the viewing experience discount. Sometimes, the attractions would be closed ahead of the time. Many enthusiastic tourists have not arrived at the bottom of the underground forest. And then, the staff would persuade the tourists to get back in the original way. And some tourists don't understand the staff. They would have a dispute or even conflict. Due to the deficiency of communication, it caused the conflict.

\section{2) It has ignored the tourist experience}

In scenic area of Changbai Mountain, it only can look at the scene and take pictures. It has no experience projects, which is the feelings of the majority of tourists. And they would feel boring. There are rich tourism resources in underground forest. However, the tourists are often just passing travelers. In addition, they only can breathe a few mouthfuls of negative oxygen ions in the air, and take a look at the ancient trees. It hasn't made much impression on the tourists. With the backward infrastructure construction of tourist attractions, the tourists often can't have services timely. The tourist experience is relatively poor.

\section{The Imperfect Regulatory System}

The regulatory of Changbai Mountain is low. Usually, the supervisory staff would make completed inspection. And they would give excellent evaluation. However, it is different. The staff in scenic attractions is more familiar with the supervisors. Each time the regulators come, the staff would tell each other. In fact, it has lost the effects of supervision. It is also helpful to form a lazy atmosphere. And then, it has reduced the quality of service to tourists. And they don't worry about being punished by the supervisor. The tourists can't reach a lot of attractions of Changbai Mountain. Most of these attractions have been destroyed with the external effects. And these attractions have a strong attraction. In order to save costs, the scenic managers of the scenic areas wouldn't repair it in time. The scenic management is lag behind. They can't find and solve problems timely. And the awareness of service and business is weak.

\section{COUNTERMEASURES OF OPTIMIZING THE MANAGEMENT OF NORTH SCENIC ATTRACTIONS OF UNDERGROUND FOREST SCENIC AREA OF CHANGBAI MOUNTAIN}

At present, China's tourism culture is still in the buyer's market stage. The consumers have absolute rights. Therefore, it can draw such a conclusion from the above problems. It is very necessary to learn from foreign advanced experience to get self-improvement in the competitive tourism market for the management of north scenic area of underground forest attractions of Changbai Mountain. The optimization measures need to be improved from multiple perspectives in parallel. It can make the adjustment specifically from the following aspects:

\section{A. The Implementation of Joint Management Model of Government and Enterprise}

In the scenic attractions, it would implement the separation of enterprise from administration. It should restore a clear administrative body, and establish the management agencies in administrative sense. Changbai Mountain is owned by the state, and the relevant government departments are responsible for supervision and protection. As a tourist resource, Changbai Mountain has been developed. It is necessary to play its economic and social benefits. In the protection of resources, the owner of tourism resources can play a better role. And in the development and management of tourism resources, the modern enterprise system is the best choice. And the enterprises are pursuit maximum interests. Through the above analysis on the advantages and disadvantages of various types of tourism scenic attractions in China, the author believes that it should separate the right of management from the ownership to make more economic benefits without damaging the tourism resources of Changbai Mountain. It should implement the management system of enterprise. Government departments have ownership and supervision. They should be responsible for planning and coordination. The enterprises are responsible for the development and operation of scenic areas, but also responsible for the protection of tourism resources. And then, it will not cause serious damage to the scenic area. Changbai Mountain is located in several jurisdictions. It is necessary to establish the management committee of Changbai Mountain Scenic Area to have the coordination. However, it should put down the rights of operation. 


\section{B. To Strengthen the Staff Management System}

\section{1) The reform of the staff compensation system}

The reform of the staff salaries system is necessary. According to the principle of efficiency and priority, the employees should receive the same pay as others doing the same work. It should provide a fair and transparent salary system for employees to get promotion. And it also should build the pay system in accordance with international standards. On the basis of efficiency and fairness, it should stimulate the enthusiasm of the staff and improve work efficiency. It is supplemented by a certain performance appraisal. And the more work is worth more pays. Everyone will be responsible for their duties. To implement the incentive mechanism is to ensure the steady growth of the companies. However, the establishment of incentive mechanism should also pay attention to the following questions. Firstly, it can't use the single incentives and means. It should establish incentive mechanism according to the specific circumstances of the staff. And it must be careful and considerate. Secondly, it is necessary to combine material and spiritual incentives. Thirdly, it should help the staff do the career planning. Fourthly, reward and punishment should be clear.

2) The underground forest work system is changed from rotation system to work post responsibility system

And the rotation system is changed into the combination system of the work post responsibility system and the regular rotation system. So, the work post responsibilities of the staff are clear. The mutual prevarication of employees will be solved. The work post responsibility of each employee should be clear. And then, it can improve the work efficiency. And then, the employees can get the appropriate reward after they have completed their own tasks. To a certain extent, it also reflects the difference among the different employees.

\section{3) To improve the quality of staff and service levels}

It should strengthen the training of staff, build knowledge-based, learning staff, and improve service awareness of the staff. It should focus on training five types of abilities of the employees. They are thinking ability, personal mastery, the improvement of mind, and the establishment of common will. And it should carry out team learning. The management of the company should also guide the staff to establish the idea of behavior management. It should put forward that the people is the most valuable resources. It should deal with the relationship among people from the relationship, demands, motivation, mutual relations and social environment and other aspects. The tourism industry is the service industry. The employees must establish the management thinking of behaviors. And it would bring better business benefits for the enterprises.

\section{To Speed up the Improvement of Tourist Management System}

1) To strengthen the guidance and education to tourists

It should make the safety knowledge and environmental interpretation educate tourists. In addition, it also can use the following ways. It should set warning signs and environmental protection signs in the appropriate position.
In the scenic entrance, it should make publicity blackboard newspaper and broadcast voice materials to guide tourists to comply with scenic management regulations. It should educate the tourists consciously make self-restraint and protect the environment. And the tourists shouldn't throw garbage, and try to avoid the destruction of the environment.

\section{2) To establish tourist participation system}

The establishment of tourist participation system can narrow the distance between managers and tourists, and reduce conflict with tourists. And in the end, it can ease the pressure on staff. For the tourists, it is also the opportunity to learn and understand the scenic area. And it also can enhance the environmental awareness to protect the scenic area. It should use the following methods to establish tourist participation system. Firstly, it can solicit volunteers. Secondly, it can provide internship opportunities for college students. Thirdly, it can select the best tourists in each year. Fourthly, it can solicit the views of tourists through the WeChat and other network platform. And it can establish survey of customer satisfaction.

\section{3) To enhance the tourist experience}

In the development process, the tourists should participate in the tourism. And then, the tourists should abandon the past fancy tour. The local cultural tourism projects can be introduced to the scenic area with great national characteristics. For example, the tourists can taste food, dance, and enjoy folk customs. The tourists can participate in the experience of the cultural landscape.

\section{To Improve the Supervision System of Scenic Area}

\section{1) To improve the supervision and management system}

From the perspective of the development of the tourism, and it should study the legal system for the management of scenic attractions. And then, it can improve the tourism industry development.

From the perspective of the enterprises, the management of tourist area should also immediately start the law construction of tourism scenic management. For the situation of the scenic area, many authorities develop local tourism management regulations. And the rules and regulations of the scenic management department are relatively in small scale. It has seriously restricted the protection of tourist attractions and norms. Therefore, the enterprises should vigorously develop the appropriate supervision and management system to standardize the enterprise management staff and tourists. The laws and regulations of scenic area management should be as specific as possible. And then, it can increase the operability, compatibility and unity. And it should increase the construction of law enforcement team to improve the level of law enforcement. When it makes the strong law enforcement to deal with illegal events, it should knock down the projects that would destroy the image of scenic attractions according to laws and regulations.

2) To improve the supervision and accusation mechanism

And it should vigorously promote the supervision and accusation mechanism through the network, telephone, 
WeChat, e-mail and other platforms. The responsibility should be clear. Also, it should raise awareness. And it can warn the corresponding violations. And then, it can make reward and punishment for those people.

3) To improve the collection system of grassroots opinion

As a service-oriented enterprise, in tourism enterprises, the management staff and grass-roots employees should establish a sense of service. And the spirit of customer service should always be the center of the work. And the most important thing is to collect tourist opinions. It should always concern about the consumer demands, as well as the opinions of the work, which is essential for the enterprises.

\section{CONCLUSION}

There are many problems in the management of underground forest attractions in Changbai Mountain. Through the analysis and research of these problems, the corresponding rationalization suggestions are put forward. And to a certain extent, it can improve the overall management of underground forest attractions. And it can improve the overall image of the scenic attractions and increase the tourists' psychological satisfaction. Also, it has developed the economic needs of the attractions. And it has promoted the development of the underground forest attractions. And then, it makes scenic attractions increasingly popular and international. And it has formed the unity of social benefits, environmental benefits and economic benefits. With the trend of tourism industry, it should strive to enhance themselves with the development of the times. The underground forest attractions can be shaped into a classic brand.

\section{REFERENCES}

[1] Zhang Yingchao. Analysis on the related problems of the management of tourism scenic attractions [J]. China Science and Technology Expo, 2013,32 (5)

[2] Liu Mingju, etc. On sustainable development of north scenic area of Changbai Mountain [J]. Taxation \& Economy, 2015 (5)

[3] Gao Peng, Liu Jia. Suggestions on the development of underground forest attractions [J]. Tourism Science, 2004 (2)

[4] Liu Mingju, Yuan Fang. On the study of tourism resources [J]. Taxation and Economy, 2016 (1)

[5] Qiao Shuying, Chen Nan. The management of scenic attractions and countermeasures in Shijiazhuang [J]. Knowledge Economy, 2013 (6)

[6] Jin Xiaozhe. Scenic area can not be completely "development zone" [J]. China Economic Weekly, 2013 (3)

[7] Zhao Yini. Thinking on the management of scenic attractions and the promotion of service quality $[\mathrm{J}]$. Journal of Guizhou Industry Polytechnic College, 2012 (4)

[8] Zhang Rensheng. A new strategy for environmental management of tourist attractions [J]. China Business, 2012. (35)

[9] Li Xiao Bing. The development and innovation of tourism scenic management model - Reflection on the management mode of scenic area in Lijiang [J]. Century Bridge, 2012 (11)

[10] An Dong. Comparison and analysis on different types of management models of tourist scenic attractions [J]. Shanxi Science and Technology, 2012 (3)
[11] Zhu Wei. Innovation of scenic area management from the perspective of tourism experience $[\mathrm{J}]$. Contemporary Travel: Academic Edition, 2012 (4) 